\title{
Podcasts? Why Not! - Perceptions of German Language Teachers
}

\author{
$1^{\text {st }}$ Dwi Putri Ningsih \\ Universitas Indonesia, \\ Depok, Indonesia \\ dwiputri30.dpn@gmail.com
}

\author{
$2^{\text {nd }}$ Sonya P. Suganda* \\ Universitas Indonesia, \\ Depok, Indonesia \\ sonya.puspa@gmail.com
}

\begin{abstract}
Technology and the internet affect the teaching of second/foreign language (L2). Podcasts have emerged as prominent tools for $\mathrm{L} 2$ extensive listening exercises. Data from several studies suggest that podcasts can be used in $\mathrm{L} 2$ learning to help learners improve their listening and speaking skills and promote intercultural comprehension ([1]; [2]). In addition, several attempts have been made to examine the perception and attitudes of $L 2$ learners toward the use of podcasts. The results show that L2 learners perceive podcasts as a useful tool. They are very interested and motivated to learn using podcasts [3]; [4]. Most studies have concentrated on the perceptions and attitudes of L2 learners toward the use of podcasts, and only a few have investigated this topic from $L 2$ teachers' perspectives. This paper provides an overview of L2 teachers' perceptions and attitudes toward the use of podcasts in teaching German as a foreign language. Data were collected using a questionnaire. The results revealed that more than half of the participants (77.8\% $(\mathrm{N}=\mathbf{2 7})$ ) knew about podcasts, while almost two-thirds of the participants $(63 \%(\mathrm{~N}=27))$ reported that they have never used podcasts when teaching the German language. Majority of the participants agreed that podcasts can be used in German language teaching, especially to improve listening skills. Podcasts make foreign language teaching and learning more interesting. However, there are also some drawbacks such as difficulty in finding suitable podcasts that can complement specific levels of teaching materials.
\end{abstract}

Keywords: Attitude, German Language Teacher, Perception, Podcast.

\section{Introduction}

Listening is an important skill for L2 learners because language input is realized through listening activities. Therefore, to acquire listening skills, it is important for L2 learners to get more exposure to L2 input activities. However, many teachers are not sure of how to teach listening in their classes [1]. L2 learners are expected to get more input both in the classroom and outside. However, time constraint is a limiting factor in the classroom. To overcome this challenge, teachers need to engage their learners in L2 listening experiences both inside and outside classrooms. During teaching activities in classrooms, teachers usually use the same audio learning materials from their handbooks. This begs the question whether sticking to the same teaching materials can help L2 learners engage in listening experiences outside the classroom.

To help L2 learners get more exposure to L2 input beyond the classroom, teachers can create extensive listening projects. Extensive listening refers to all types of listening activities that allow learners to receive a lot of comprehensible and enjoyable listening input [5]. For the past ten years, there has been an increasing interest in implementing extensive listening. Extensive listening projects provide L2 learners with materials to maximize L2 input. One of the tools that can be used in extensive listening projects is podcasts.

Podcasts are one of the most useful tools for learners to acquire listening skills. They can help learners experience L2 input both inside and outside classrooms. A podcast can be described as an audio or video file published via internet, designed to be downloaded to a MP3 player or a laptop for future listening [6]. However, podcasts were not originally made for L2 learning [7]. Podcasts provide L2 learners with current information and extensive sources of audio and video materials that can help them to effectively improve their language proficiency, particularly listening skills outside the classroom [8]. Podcasts allow learners large flexibility. For instance, L2 learners can choose the kind of podcasts they wish to listen to, when they want listen to them, and where they want to listen from. Based on this practicability reason, podcasts can be an effective tool to provide L2 input to learners.

The important role of podcasts in language teaching and learning has been explored by various studies, with the aim of identifying L2 learners' perceptions and attitudes. Majority of the results show that L2 learners' perceptions and attitudes toward the use of podcasts in language learning are positive ([9]; [10]). However, very little is known about teachers' perceptions and attitudes toward the use of podcasts in language teaching.

This study explores the perceptions and attitudes of teachers toward the use of podcasts in language teaching. Its findings will be instrumental in helping teachers to know and understand the type of podcasts that can help their learners get more L2 input exposure. Even though learners are able to listen to podcasts during their own free time, it is still crucial for language teachers to monitor all their listening activities and the type of podcasts that they listen to. This is because by monitoring their listening activities, teachers can help learners get effective and suitable podcasts that complement their learning materials in classrooms.

\section{Methods}

The participants in this study were 27 German language teachers $(\mathrm{N}=27)$ residing in Jakarta, Indonesia. This study used a survey with a quantitative approach. Its purpose was to obtain a snapshot of conditions, attitudes, and/or events of an entire population at a single point in time by collecting data from a sample drawn from that population. Many researchers have utilized questionnaires to identify perceptions and attitudes of learners toward the use of podcasts in L2 learning. To identify their perceptions and attitudes toward the use of podcasts in language teaching, the participants were asked to answer an online questionnaire. For the attitude questions, a Likert scale was used. The online questionnaire consisted of 
25 items of mixed closed and open-ended questions. The questionnaire was divided into three parts: participants' background, participants' experience using technology and internet, and the perceptions and attitudes of the participants toward the use of podcasts in language teaching.

The first part of the questionnaire elicited information on participants' personal background such sex, teaching experiences, working place, and the level of German language teaching. The second part the questionnaire asked participants to respond the statements provided using 4-point Likert scale (ranging from 1 to 4) and also answer open-ended questions. This part was made up of eight statements. Finally, the third part of the questionnaire was designed to elicit the participants' attitudes and perceptions toward the use of podcasts in German language teaching. In this part, the participants were asked to respond to closed questions using a 4-point Likert scale (where 1=strongly disagree, $2=$ disagree, $3=$ agree, and 4=strongly agree) and open-ended questions. Before the questionnaire was distributed to the participants, the authors conducted a pilot study by distributing the questionnaire to five German teachers who did not participate in the actual research. After the piloting stages, the authors modified and revised some questionnaire items that were unclear. The questionnaire was then distributed to German language teacher groups, and it took two weeks to collect the filled questionnaires. From the questionnaire results, the authors analyzed the mean scores of the responses of the participants using a 4-point Likert scale. The calculations for the mean scores are shown inTable 1 . In addition, the answers from the open-ended questions were analyzed and crossreferenced using the related literature review of perceptions and attitudes toward the use of podcasts in language teaching.

\begin{tabular}{|c|c|c|}
\hline No. & Mean Value & Interpretation \\
\hline 1 & $>2,5$ & Agree toward the statements \\
\hline 2 & $<2,5$ & Disagree toward the statements \\
\hline
\end{tabular}

Table 1. Mean Results Interpretation

\section{Result and Discussion}

The questionnaire was divided into three parts: participants' background, participants' experience using technology and internet, and the perceptions and attitudes of the participants towardthe use of podcasts in language teaching.

\section{A. Participants' Background Results}

The results of the first part revealed that more than half of the participants were women $(70.4 \%(\mathrm{~N}=27))$, and only a few of them were men $(29.6 \%(\mathrm{~N}=27))$. The participants teaching experiences' also varied. Participants with less than one year teaching experiences were $22.2 \%(\mathrm{~N}=27)$, participants with teaching experiences between $1-5$ years were $33.3 \%(\mathrm{~N}=27)$, participants with teaching experiences between 6-10 years were $11.1 \%(\mathrm{~N}=27)$, and participants with more than ten years teaching experience were $33.3 \%(\mathrm{~N}=27)$. From these results, more than half of the participants had relatively extensive teaching experiences, and only a few of them had less than one year teaching experience.

The participants were German language teachers from different teaching settings such as high school, university, and language courses (private courses). There were $48.1 \%$ ( $\mathrm{N}=27)$ participants who had two to three different teaching settings while the remaining $51.8 \%(\mathrm{~N}=27)$ had one fixed teaching setting. The next set of questions asked participants to provide information about the German language level that they usually teach. Half of the participants $(51.8 \%)$ reported that they taught German language for A1-A2 level, and the remaining participants $(48.1 \%)$ reported that they taught from A1-A2 level (beginner) to B1-B2 level (intermediate). Interestingly, there were no participants who taught German language at the C1-C2 level (advanced).

\section{B. Participants' Experiences in the Use of Technology and Internet}

This section of the questionnaire required the participants to provide information on how they incorporate technology and internet in their teaching activities. All the participants $(\mathrm{N}=27)$ indicated that they frequently use technology and internet in their teaching activities. The next set of questions sought to find out the participants' experiences in using technology and internet during their teaching activities. The results revealed that $81.5 \%(\mathrm{~N}=27)$ of the participants did not experience difficulties in using technology and internet during teaching activities while $18.5 \%(\mathrm{~N}=27)$ of the participants reported contrary. The obstacles included bad internet connection, insufficient number of laptops or computers, technical problems (e.g., being unable to download teaching materials), and difficulties in finding suitable teaching and learning materials.

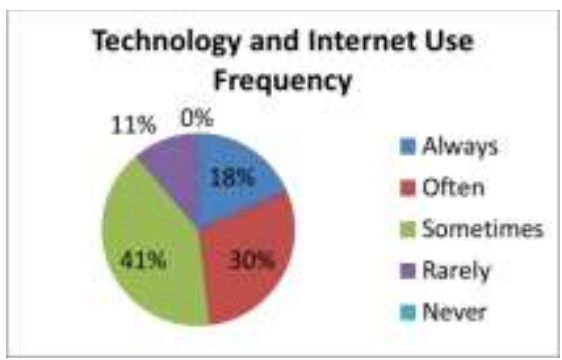

Fig. 1. Technology and Internet Use Frequency

Figure 2 shows the results of how frequent the participants used technology and internet in teaching activities. It shows that most of the participants were already incorporating technology and internet in their teaching activities, but the frequency of each participant varied. Surprisingly, none of the participants had never used technology and internet. These results imply that technology and internet play a crucial role in German language teaching. The next set of questions required the participants to provide their opinions on a statement that reflected their perceptions about the use of technology and internet in teaching activities.

\begin{tabular}{|c|c|c|c|c|c|}
\hline No. & Questions & Min & Max & SD & Mean \\
\hline $\mathbf{1}$ & Q9 & 1 & 4 & 1,01 & 3,41 \\
\hline $\mathbf{2}$ & Q10 & 1 & 4 & 0,89 & 3,52 \\
\hline $\mathbf{3}$ & Q11 & 1 & 3 & 0,75 & 1,56 \\
\hline $\mathbf{4}$ & Q12 & 1 & 4 & 0,73 & 1,33 \\
\hline
\end{tabular}

Table 2. The Results of Participants' Perceptions toward the Use of Podcasts

Question 9 contained the statement "Using technology and internet is very important in the context of language teaching and learning nowadays," and its mean score was 3.41 (>2.5). These results imply that the participants agreed on the notion 
that the use of technology and internet nowadays plays an important role in the context of language teaching and learning, and the theyperceived it as a positive thing. Incorporating various technologies and the use of the internet into teaching activities can make the teaching and learning processes more attractive and interesting. This is because technology and internet are some of the main things that learners interact with on a daily basis. Question 10 contained the statement "Technology and internet can help teachers to prepare teaching materials," and its mean score was 3.52 $(>2.5)$. These results imply that the participants perceived technology and internet as useful tools that can help them prepare teaching materials.

Question 11 was the statement "the use of technology and internet may interfere with the teaching process," and its mean score was $1.56(<2.5)$. These results imply that the participants disagreed with this statement. The participants believed that the use of technology and internet cannot interfere with the teaching process. Question 12 was the statement "I am not interested in using technology and internet in my teaching activities," and it had a mean score of $1.33(<2.5)$. These results imply that the participants disagreed with this statement. Therefore, the participants were very willing and interested in incorporating technology and internet into their teaching activities.

The results reveal that German language teachers are very open and interested in incorporating technology and internet into their teaching and learning activities. However, they still face difficulties when it comes to the practical application of technology in classrooms. Some of the challenges that they often experience are: unstable internet connection, limited number of mobile devices to provide more teaching and learning materials, and difficulties in finding the most suitable teaching and learning materials. In some instances, the materials cannot be downloaded or L2 learners are already familiar with the materials so they cannot be used again in the classroom.

\section{Participants' Perceptions and Attitudes toward the Use of Podcasts}

This part asked questions regarding participants' perceptions and attitudes toward the use of podcasts in German language teaching. Figure 2 shows that more than half of the participants $(\mathrm{N}=27)$ knew podcasts, and only a few of them did not know about podcasts. These results imply the fact that the participants already had knowledge and information about podcasts and how they can be used. Surprisingly, only a few of the participants were already using podcasts in German language teaching. Figure 3 shows that there was no participant who often used podcasts in their teaching activities.

\section{Knowing Podcasts}

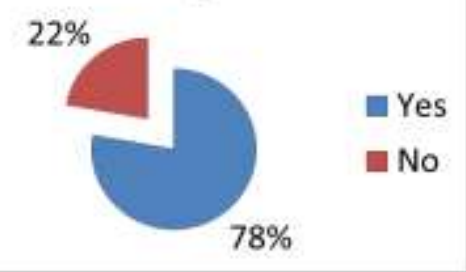

Fig. 2. Number of Participants Knows about Podcasts

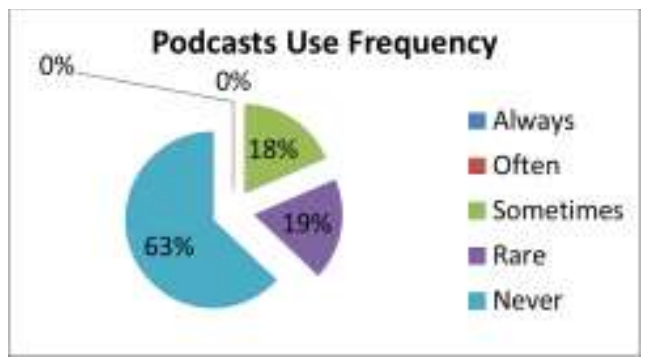

Fig. 3. Frequency Use of Podcast by Participants

Figure 5 presents the frequency of podcast use among the participants, and it shows that the participants rarely used podcasts in their teaching activities. Comparing the results between the frequency podcasts use and that of using technology, we can deduce that although all the participants claimed that they had already incorporated technology and internet into their teaching activities, only a few of them had actually used podcasts in German language teaching. This is corroborated by the fact that almost two-thirds of the participants $(63 \%)$ claimed that they had never used podcasts in teaching German language (Fig. 5). There were only a few participants who used podcasts sometimes and rarely in their teaching activities. The use of podcasts in language teaching is not something new. These results, therefore, imply that even though the participants knew about podcasts, they were still not using them in their teaching activities.

Table 6 shows the results of the part of the questionnaire that sort to inquire about the participants' perceptions toward the use of podcasts in language teaching. This part had eight statements with a 4-points Likert scale.

\begin{tabular}{|c|c|c|c|c|c|}
\hline No. & Questions & Min & Max & SD & Mean \\
\hline $\mathbf{1}$ & Q15 & 2 & 4 & 0,71 & 3,15 \\
\hline $\mathbf{2}$ & Q16 & 2 & 4 & 0,69 & 3.11 \\
\hline $\mathbf{3}$ & Q17 & 1 & 4 & 0,73 & 3.07 \\
\hline $\mathbf{4}$ & Q18 & 1 & 4 & 0,86 & 2,15 \\
\hline $\mathbf{5}$ & Q19 & 1 & 4 & 0,84 & 1,89 \\
\hline $\mathbf{6}$ & Q20 & 1 & 4 & 0,78 & 3,19 \\
\hline $\mathbf{7}$ & Q21 & 1 & 4 & 0,92 & 3,00 \\
\hline $\mathbf{8}$ & Q22 & 1 & 3 & 0,75 & 2,04 \\
\hline
\end{tabular}

Table 3. The Results of the Participants' Perceptions toward the Use of Podcasts

Question 15 had the statement "Podcasts are a useful tool that can be used to promote learning processes, particularly teaching and learning listening skills," and its mean score was 3.15 (>2.5). This implies that the German language teachers agreed that podcasts can be useful in teaching activities. Surprisingly, despite their little experience in using podcasts in teaching activities, the participants had positive attitudes toward the use of podcasts, especially in teaching listening skills. These results corroborate the ideas of Cahyani and Cahyono [11], who assert that teachers have positive attitudes toward the use of technology in classrooms. They also believe that to develop L2 learners' language skills, teachers should use different types of technology. Question 16 had the statement "Materials from podcasts are suitable for inclusion in language teaching and learning processes," and its mean score was $3.11(>2.5)$. This implies that the participants agreed that materials from podcasts are suitable for their German language teaching activities. These results further support the idea of Mustafina [12], who opines that language teachers 
should see the necessity to promote and integrate information and communication technology (ICT) in their teaching and learning processes. By doing this, teachers will have new and innovative ways of instructing their L2 learners.

Question 17 had the statement "The materials from podcasts are better being used only as additional teaching or learning materials," and its mean score was 3.07 (>2.5). These results imply that the participants agreed that podcast materials can be used as additional teaching materials. These results support the findings of previous studies, which have reported that learners have positive attitudes toward the use of podcasts because they see podcasts as an attractive and helpful tool. Moreover, teachers, as the main facilitators, should be able to give instructions using podcasts. Question 18 had the statement "Podcast materials do not complement my teaching materials," and its mean score was $2.15(<2.5)$. This implies that the participants disagreed with the statement. Therefore, they actually believed that podcast materials complement their teaching materials. This alludes to the fact that the participants were positive about listening materials from podcasts being used together with their current teaching materials. However, teachers need to ensure that the podcasts they use concur with their teaching materials and that they also match the current level of their L2 learners' language proficiency.

Question 19 had the statement "The use of podcast materials will disrupt language teaching and learning activities," and its mean score was $1.89(<2.5)$. These results imply that the participants disagree the use of the podcasts will disrupt the teaching process. This reflects the positive attitudes of the participants toward the use of podcasts. Question $20 \mathrm{had}$ the statement "Through podcasts, I can provide L2 learners with authentic materials," and its mean score was $3.19(>2.5)$. These results signify that the participants agreed that using podcasts can help them provide their L2 learners with authentic materials. Moreover, the results corroborate the findings Li's [13] study, which explained that podcasts help students get more authentic materials and personal experience in learning a L2.

Question 21 had the statement "Teaching German language using podcasts is new for me," and its mean score was $3.00(>2.5)$. These results signify that the participants agreed that the use of podcasts is still a new thing for German language teaching. However, the participants seemed to believe that in the meantime, the use of ICT in language teaching and learning processes cannot be avoided. This also suggests that it is necessary for language teachers to know and understand how to use various teaching methods and teaching tools, such as podcasts. Question 22 had the statement "I am not sure whether the teaching materials from podcasts can be used in my teaching activities," and its mean score was 2.04 $(<2.5)$. These results imply that the participants are ready to incorporate the materials from podcasts into their teaching activities. It further signifies that the participants have a positive attitude toward the use of podcasts.

The results of the participants' $(\mathrm{N}=27)$ responses to the statement "Are you interested in using podcast materials in your teaching activities?" are shown in Table 7 below. From this table, we can see that $11.1 \%$ the participants were interested in using podcasts, $70.4 \%$ could consider using podcasts, and only $18.5 \%$ hesitated to use them.

\begin{tabular}{|c|c|c|}
\hline No & Answers & Participants \\
\hline $\mathbf{1}$ & No & $18,5 \%$ \\
\hline $\mathbf{2}$ & Maybe & $70,4 \%$ \\
\hline $\mathbf{3}$ & Yes, Sure & $11,1 \%$ \\
\hline
\end{tabular}

Table 4. Participants' responses to using podcasts

The last open-ended question had the statement "What is your opinion on podcasts being used in the context of German language teaching?" The participants had varied opinions when it came to this question. Here are some of their remarks:

"It helps me give more listening activities to L2 learners, and it also helps them improve their listening skills."

"By using podcasts, teaching activities might get more attention from L2 learners."

"It is good, and can probably be used as a supplementary material in teaching L2learners."

"Pay more attention to L2 learners' language proficiency, and find most suitable podcasts for them."

"An innovative way to teach listening skills and elicit an interesting discussion, particularly for beginner and even advanced level L2 learners"

From these results, we can conclude that the participants had a positive attitude and perception toward the use of podcasts in teaching and learning processes. However, more than half of them had not yet used podcasts in language teaching. One of the reasons as to why they had not used podcasts in their teaching and learning activities is that they were still not sure of how to implement the use of podcasts in their classrooms. In addition, it is difficult for them to find suitable podcast materials that can complement their current teaching materials, and it takes a lot of effort to find appropriate podcasts that match L2 learners' current language proficiency. The results of the open-ended questions revealed that most of the participants were interested in learning more on how to use podcasts in German language teaching activities. These results match the findings of previous studies ([14]; [15]), which reported that teachers have positive attitudes toward the implementation of ICT in teaching and learning processes. This positive attitude might influence the learning motivation of L2 learners. However, it is important to note that some participants were still reluctant to integrate podcasts in their German language teaching activities.

\section{Conclusion}

The aim of this study was to examine the attitudes and perceptions of German language teachers toward the use of podcasts in language teaching. This study found that the participants had a positive attitude toward the use of podcasts in teaching and learning activities. The findings of this research reveal that to effectively use podcasts, teachers should have a positive attitude and perception toward them. The insights gained from this study suggest that teachers should be more open to the use of podcasts as a teaching tool. However, they must carefully select the most suitable podcast materials for their teaching. Notably, the selection process is still viewed as the most prominent challenge. In spite of this, teachers can still choose authentic listening materials that corroborate their teaching materials. This study is one of the first attempts to thoroughly examine the perceptions and attitudes of language teachers toward the use of podcasts. The 
generalizability of these results is subject to certain limitations. For instance, the number of participants and lack of step by step interviews were not done by this study. Therefore, future studies shouldexplore this area of research in greater detail. For instance, they should pay attention to how language teachers assess their students' performance after using podcasts in their teaching activities.

\section{Acknowledgment}

This work was supported by Universitas Indonesia's Research Grant (PITMA B 2019) managed by DRPM UI/Indonesian Ministry of Research and Technology and the Higher Education's Research Grant (PDUPT 2019) managed by DRPM UI. We would like to express our sincere gratitude to Dr. Sonya Puspasari Suganda, S.S., M.A. for her patience and invaluable support during the preparation process of this article.

\section{References}

[1] Vandergrift, L., \& Goh, C. C. M. (2012). Teaching and learning second language listening - Metacognition in action. New York: Routledge Taylor and Francis. https://doi.org/10.4324/9780203843376

[2] Ramli. (2018). The use of podcast to improve students' listening and speaking skill for EFL learners. Journal of Applied Linguistics and Language Research, 5(2), 1-10.

[3] Gribbins, M. (2007). The perceived usefullbess of podcast in higher education: a survey of students' attitudes and intention to use. In The Second Midwest United States Association for Information Systems. Illinois, Springfiel: MWAIS.

[4] Chan, W. M. (2011). Students' perceptions of and attitudes towardss podcast-based learning - a comparison pf two language podcast projects. Electronic Journal of Foreign Language Teaching, 8(1), 312335 .
[5] Renandya, W. A., \& Farrell, T. S. C. (2011). "Teacher, the tape is too fast!" Extensive listening in ELT. ELT Journal, 65(1), 52-59. https://doi.org/10.1093/elt/ccq015

[6] McMinn, S. (2008). Podcasting possibilities: increasing time and motivation in the language learning classroom. European Institute for E-Learning. Learning Forum, 212-215.

[7] McBride, K. (2009). Podcast and second language learning : promoting listening comprehension and intercultural competence. In L. B. Abraham \& L. Williams (Eds.), Electronic Discourse in Language Learning and Language teaching (pp. 153-167). Amsterdam: John Benjamins Publishing Company. Retrieved from https://books.google.co.id/books?id=n92wO1rdevgC\&printsec=frontc over\# $\mathrm{v}=$ onepage $\& \mathrm{q} \& \mathrm{f}=$ false

[8] Cross, J. (2014). Promoting autonomous listening to podcasts: A case study. Language Teaching Research, 18(1), 8-32. https://doi.org/http://dx.doi.org/10.1177/1362168813505394

[9] Farshi, N., \& Mohammadi, I. Z. (2013). Use of podcasts in effective teaching of vocabulary: Learners' attitudes, motivations and limitations. Theory and Practice in Language Studies, 3(8), 81-1386. https://doi.org/doi:10.4304/tpls.3.8.1381-1386

[10] Hasan, M. M., \& Tan, B. H. (2013). Podcast applications in language learning: A review of recent studies. English Language Teaching, 6.

[11] Cahyani, H., \& Cahyono, B. Y. (2012). Teachers' attitudes and technology use in Indonesian EFL classrooms. TEFLIN Journal, 130148 https://doi.org/http://dx.doi.org/10.15639/teflinjournal.v23i2/130-148

[12] Mustafina, A. (2016). Teachers' attitudes towards technology integration in a Kazakhstani secondary school. Nternational Journal of Research in Education and Science, 322-332.

[13] Li, H. (2012). Using podcasts for learning English: perceptions of Hong Kong secondary 6 ESL students. ELT World Online, 4, 78-90.

[14] Cox, M., Abbott, C., Webb, M., Blakeley, B., Beauchamp, T., \& Rhodes, V. (2004). ICT and attainment: A review of the research literature. the British Educational Communications and Technology Agency. England.

[15] Rana, N. (2012). A study to asses teacher educators' attitude towardss technology integration in classrooms. MIER Journal of Education Studies, Trend and Practices, 2(2), 190-205. 